\title{
MEMÓRIA E CIDADE: PATRIMÔNIO, CULTURA E HISTÓRIA DE NOVA IGUAÇU/RJ
}

\author{
Elis Regina Barbosa Angelo ${ }^{1}$ \\ Isabela de Fátima Fogaça²
}

\begin{abstract}
Resumo: Este artigo traz uma síntese das pesquisas e atividades desenvolvidas, resultados e desdobramentos do projeto "Patrimônio Histórico e Cultural de Nova Iguaçu: Relações Simbólicas, Sociedade e Turismo", que teve como objetivo organizar informações para a construção de uma cartilha do patrimônio histórico e cultural do município de Nova Iguaçu/RJ, voltada ao Ensino Fundamental. Portanto, seus resultados buscaram contribuir para despontar entre estudantes e educadores de Nova Iguaçu uma nova forma de se ver e de existir para si e para o mundo, além de sinalizar para o aprendizado e reconhecimento da história da cidade e importância da colaboração e da multiplicação do conhecimento sobre o patrimônio cultural.
\end{abstract}

Palavras-chave: Patrimônio. Memória. Cidade. Nova Iguaçu. Educação Patrimonial.

Abstract: This article provides a summary of the research and activities developed, results and developments of the project "Historical and Cultural Heritage of Nova Iguaçu: Symbolic Relations, Society and Tourism", which aimed to organize information for the construction of a booklet of historical and cultural heritage Nova Iguaçu / RJ, focused on Elementary Education. Therefore, its results sought to contribute to the emergence of Nova Iguaçu students and educators in a new way of seeing and existing for themselves and for the world, in addition to signaling the learning and recognition of the city's history and importance of collaboration and multiplication of knowledge about cultural heritage.

Keywords: Heritage; Memory. City. Nova Iguaçu. Patrimonial Education.

\footnotetext{
1 Pós - doutora, Doutora e Mestre em História pela PUC/SP; Mestre em Turismo Ambiental e Cultural Planejamento e Gestão pela Unibero, Bacharel em Turismo pela PUC/ Campinas. Professora Adjunta da Universidade Federal do Rio de Janeiro, atuando no curso de Pós-graduação em Patrimônio, Cultura e Sociedade e no curso Bacharelado em Turismo. E-mail: elis@famiaangelo.com

${ }^{2}$ Doutora em Geografia pela UNESP/ Rio Claro; Mestre em Turismo e Hotelaria pela UNIVALI/ SC; Bacharel em Turismo pela UEPG; Licenciada em Geografia pela UNB. Professora Adjunta da Universidade Federal do Rio de Janeiro, atuando no curso de Pós-graduação em Patrimônio, Cultura e Sociedade e no curso Bacharelado em Turismo. E-mail: isafog@hotmail.com
} 


\section{Introdução}

As cidades estão em constante transformação, resultado de processos sociais, econômicos, culturais, ecológicos e políticos por que passam a sociedade em cada período, e que, consequentemente, refletem-se de forma material na paisagem urbana e simbólica, bem como nas relações que ali se desenvolvem. Portanto, a cidade é produto do processo histórico de produção e reprodução do espaço pela sociedade.

Nesse sentido, a forma de pensar e planejar a cidade contemporânea, cuja relação global e local se aprofunda cada vez mais, passa a ter a cultura como elemento central, uma vez que, como esclarecem Vaz e Jacques (2001, p.673), “[...] uma das condições exigidas das cidades que almejam se inserir na rede global é de apresentar entre os itens que compõem a qualidade de vida urbana um adequado padrão cultural".

Verifica-se que as propostas tanto de apropriação turística quanto de renovação dos espaços urbanos têm sido formas de reinventar as relações dos sujeitos com as memórias dos lugares e a cultura, bem como a identidade cultural e o patrimônio ali construído. Por consequência, a educação patrimonial passa a ganhar destaque no âmbito das ações públicas e privadas de produção desse espaço.

Dentro dessa perspectiva, no final do ano de 2013, um grupo de professores e estudantes da Universidade Federal Rural do Rio de Janeiro (UFRRJ), imbuídos do propósito de trazer essa discussão para o âmbito da Baixada Fluminense e, especialmente, para o município de Nova Iguaçu, iniciou o projeto "Patrimônio Histórico e Cultural de Nova Iguaçu: Relações Simbólicas, Sociedade e Turismo", que teve como objetivo organizar informações para a construção de uma cartilha do patrimônio histórico e cultural do município de Nova Iguaçu/RJ, que serviria como material complementar às atividades do Ensino Fundamental, cujo destaque fosse a história, a cultura e o turismo como temas transversais.

Assim, nos anos de 2014 e 2015, o projeto buscou na construção dos elementos de memória e história a representação da cultura, seja nos espaços públicos ou privados do município de Nova Iguaçu, especialmente tendo como base as histórias de vida dos sujeitos sociais e suas relações com a memória local. A ideia era incorporar o patrimônio cultural no cotidiano dos escolares, visto que muitos eram desconhecidos por boa parte da população e estão em processo de degradação, como a fazenda São Bernardino, e por isso necessitam da mobilização social para a sua preservação. Portanto, fomentar novos olhares sobre o cotidiano que viviam.

Deste modo, as edificações históricas, as tradições, as danças, as músicas, a culinária, as festas populares, as manifestações religiosas, enfim, a própria história construída, e que deve constituir a memória de seu povo, foram levantadas e analisadas para comporem temas a serem discutidos, principalmente, no cotidiano escolar.

Nesse sentido, o projeto localizou e descreveu os bens culturais e suas transformações, em contextos específicos e locais, por meio de pesquisas etnográficas e documentos analíticos produzidos pela equipe de trabalho da UFRRJ, registrando tais bens materiais e imateriais a partir do preenchimento das fichas do Instituto do Patrimônio Histórico e Artístico Nacional (IPHAN); localizou, criou e sistematizou documentos e referências sobre esses bens culturais; e construiu mapas temáticos destes bens, para compor uma cartilha e estimular roteiros 
histórico-culturais no município. Principalmente no intuito de colaborar para a investigação, houve o aprofundamento teórico e prático dos rumos e significados das pesquisas e políticas públicas na área das culturas populares, simbólicas e tradicionais correlacionadas à educação e ao desenvolvimento socioeconômico na região da Baixada Fluminense.

Em sua vertente, ainda mais extensionista, objetivou tornar tanto os estudantes universitários envolvidos quanto aqueles do Ensino Fundamental, principal público-alvo do produto gerado pelo projeto, a cartilha, partícipes desse trabalho de pesquisa, através da identificação dos bens culturais que fazem parte da sua memória e de suas famílias. Além de disponibilizar ao público o resultado do trabalho de pesquisa, anteriormente realizado, a fim de ampliar junto aos diferentes atores sociais as informações coletadas e definir melhores formas de dispô-las em um material didático complementar às atividades do Ensino Fundamental.

$\mathrm{O}$ registro das informações coletadas foi alcançado com a elaboração de fichas do patrimônio, organizando todo um acervo material e imaterial, e sua exploração foi organizada a partir da colaboração dos alunos do Educandário Nova Grécia, que, ao participarem da formação visual dos bens materiais e imateriais, também protagonizaram o reconhecimento da história da cidade. Essa forma de atuação almeja promover um olhar voltado para a educação patrimonial colaborativa, na qual todos são sujeitos do processo.

Nesse sentido, este artigo traz uma síntese das pesquisas e atividades desenvolvidas e um relato dos resultados e desdobramentos do projeto, visando que ações como essa sejam valorizadas e multiplicadas nos demais municípios da Baixada Fluminense.

\section{O projeto "Patrimônio Histórico e Cultural de Nova Iguaçu: Relações Simbólicas, Sociedade e Turismo}

O projeto "Patrimônio Histórico e Cultural de Nova Iguaçu: Relações Simbólicas, Sociedade e Turismo" teve como objetivo organizar informações para a construção de uma cartilha do patrimônio histórico e cultural do município de Nova Iguaçu/RJ, uma cidade que, por um lado, mostra-se como uma das mais prósperas da região, com o $7^{\circ}$ Produto Interno Bruto do Estado (BRASIL/IBGE, 2015), e por isso atrai a atenção de grupos de investidores, mas, por outro lado, torna-se muito fragilizada pela imagem e estereótipo a ela atribuído de cidade-dormitório, desordenada e violenta.

Durante as pesquisas bibliográfica, documental e de campo necessárias à execução do projeto, pôde-se perceber o quão rico é o patrimônio cultural material e imaterial presente no município de Nova Iguaçu, bem como sua potencialidade para impulsionar a autoestima de sua população por meio da disseminação de conhecimento, pois, de acordo com Andrade (1987, p.65),

Só o conhecimento direto e não apenas ligeiro dessas obras do passado [...], criadas com tamanho esforço e, às vezes, em condições tão pouco favoráveis, é que se aprende a considerá-las no seu verdadeiro sentido. Só do convívio com os monumentos e com a sua história poderá nascer a estima sincera que eles devem inspirar. 
Dessa metodologia aplicada, buscou-se a conformação de um modelo para posterior aplicação nas demais cidades da Baixada Fluminense, que apresentam semelhantes carências no que diz respeito à produção e divulgação de informações e registros culturais. Num primeiro momento, a metodologia focalizou na criação de instrumentos abertos aos pontos de vista e expectativas dos portadores de tradições culturais específicas, pressupondo a identificação da dinâmica própria dessas localidades e tradições, sem pretender, portanto, "engessar" suas formas e conteúdos no tempo e no espaço, o que é fundamental, pois a questão é ampla e complexa, a ponto de trazer elementos totalmente mutáveis.

Foram também investigados arquivos documentais municipais, fontes bibliográficas, bem como as próprias comunidades-alvo no município de Nova Iguaçu. Além da análise documental e bibliográfica, o método de investigação foi pautado em entrevistas, justamente pelo seu caráter dialógico e aberto à interação com as comunidades detentoras do conhecimento. As entrevistas focalizaram a história oral e, eventualmente, as histórias de vida de pessoas consideradas peças-chave na dinâmica da cultura imaterial do município, especialmente por formarem um acervo vivo de histórias e memórias.

A organização da pesquisa foi efetivada com base em três frentes distintas: o patrimônio material, o imaterial e a educação patrimonial. A extensão propriamente dita aconteceu com atividades envolvendo a comunidade, especificamente encontros participativos com realização de oficinas, além de produção e distribuição de uma cartilha como produto final do projeto.

A cartilha elaborada tem como objetivo a promoção da educação patrimonial na cidade de Nova Iguaçu, baseada na colaboração dos alunos do Ensino Fundamental. Essa colaboração atende aos requisitos de participação conjunta e formulação de ideias acerca da "leitura da cidade". Assim, projetou-se uma forma de ler o patrimônio histórico e cultural e disseminá-lo na educação básica, seja como modelo de colaboração, seja como proposta de pertencer.

Logo, antes da intervenção com as crianças (projeto-piloto), experiência que ocorreu no Educandário Nova Grécia, que teve como objetivo levantar em meio aos educandos a melhor forma e linguagem para a elaboração da cartilha sobre o patrimônio de Nova Iguaçu, o grupo envolvido fez a inventariação do patrimônio cultural material e imaterial presente no município. Nesse sentido, foi possível identificar exemplares da arquitetura religiosa como a Matriz da Freguesia de Santo Antônio Orago da Jacutinga ${ }^{3}$, construída em estilo neogótico; a Capela da Fazenda da Posse ${ }^{4}$, único remanescente da antiga Fazenda da Posse, construída por volta de 1760, pelo bispo do Rio de Janeiro (MONUMENTOS DO RIO, s/d); a Capela Nossa

\footnotetext{
3 A Matriz passou por muitas transferências no decorrer da história religiosa da cidade. Inicialmente, em 1711, estava localizada em uma colina; depois, em 1785, foi construída outra edificação perto da colina da antiga Matriz. Em 1791 concluíram a construção da torre do sino da atual Igreja Santo Antônio da Prata. A igreja foi transferida novamente, em 1862, para a atual Matriz de Santo Antônio de Jacutinga, em Nova Iguaçu, que na época denominava-se Arraial de Maxambomba (PARÓQUIA SANTO ANTÔNIO DE JACUTINGA, s/d). Na contemporaneidade, a igreja foi significativamente descaracterizada, principalmente no que se refere às suas cores, que nada coincidem com o estilo da igreja, o neogótico.

${ }^{4}$ Denominava-se Capela Nuestra Señora Madre de Dios, nome em espanhol por conta da época da união das Coroas de Portugal e Espanha (DO NOME, 2011). Foi, na sua origem, uma das seis capelas filiadas à Freguesia de Santo Antônio de Jacutinga. A nave da capela se estende para o exterior em um alpendre com seis colunas toscanas apoiadas em um patamar levemente elevado do terreno. Foi tombada provisoriamente pelo Instituto Estadual do Patrimônio Cultural - INEPAC em 1989 (RIO DE JANEIRO/ INEPAC, s/d-e).
} 
Senhora de Guadalupe ${ }^{5}$, que mistura marcas de diferentes épocas, predominando um gosto barroco, com provável influência jesuítica; a Igreja Nossa Senhora da Conceição de Marapicu ${ }^{6}$, construída em 1736; e a Igreja Santo Antônio da Jacutinga da Prata ${ }^{7}$, construída em 1773, na margem do antigo caminho que ligava o engenho de Maxambomba, atual Nova Iguaçu, à Fazenda do Brejo, hoje Belfort Roxo, algumas tombadas pelo Instituto Estadual do Patrimônio Cultural (INEPAC) do estado do Rio de Janeiro.

Também foram inventariados exemplares da arquitetura ferroviária como a Estação Ferroviária Rio D’Ouro ${ }^{8}$, construção típica da arquitetura das estações ferroviárias do início do século XX, com frontões nas laterais (RIO DE JANEIRO/ INEPAC, s/d-a); a Estação Ferroviária Jaceruba (São Pedro) ${ }^{9}$, construída no início do século XX, integrada à linha principal da Estrada de Ferro Rio D’ouro, última a fechar na década de 1970; a Estação Ferroviária de Tinguá ${ }^{10}$, típica do início do século XX (RIO DE JANEIRO/ INEPAC, s/d-b); e a Estação Vila de Cava ${ }^{11}$, construída com dois pavimentos, em estilo misiones simplificado ou californiano, em voga nos decênios de 1930 e 1940, da mesma forma, todas tombadas pelo órgão de proteção do patrimônio do estado, INEPAC (ESTAÇÕES FERROVIÁRIAS DO BRASIL, s/d).

Quanto à arquitetura civil e conjuntos arquitetônicos, destaca-se entre os bens inventariados a Fazenda São Bernardino, localizada dentro do território da Antiga Vila de Iguassú, datada da segunda metade do século XIX (1875), construída em estilo neoclássico e tombada como patrimônio artístico e histórico pelo Instituto do Patrimônio Histórico e Artístico Nacional - IPHAN (PARÓQUIA NOSSA SENHORA DA CONCEIÇÃO -

\footnotetext{
${ }^{5}$ Originalmente alocada em meio a ampla área, sobre pequena elevação, pelo capitão Manuel Pereira Ramos, e consagrada com uma procissão solene em 4 de março de 1750. Acoplada à nave, do lado esquerdo, há pequena sineira e em sua fachada (portal) está marcada a data de sua conclusão, 1753. Tombada pelo INEPAC provisoriamente em 1989 (RIO DE JANEIRO/ INEPAC, s/d-f).

${ }^{6}$ Está situada no alto de uma colina circundada pela estrada de Madureira e constitui um marco importante na paisagem da região. O acesso é feito por caminho calçado de pedras, com espaços amplos ao redor, e tem aos fundos um cemitério. A fachada é simples com frontão triangular, a torre, acoplada ao corpo principal, é arrematada por uma pirâmide de concreto e abriga o sino, datado de cerca de 1850. Construída em 1736 nas terras do capitão Manuel Pereira Ramos, no ano de 1752, recebeu, por autorização do bispo do Rio de Janeiro, uma "tribuna de honra". Foi ampliada e reformada em 1853, e no século XX teve o interior descaracterizado com o desaparecimento dos altares colaterais e a venda da talha e do altar-mor. Foi tombada provisoriamente pelo INEPAC em 1989 (RIO DE JANEIRO/ INEPAC, s/d-g).

${ }^{7}$ A igreja passou por várias reformas, com alterações no altar-mor e no púlpito e a retirada do cruzeiro que ficava na parte frontal. De fachada simples e ornamentação classicizante, a igreja tem pequena torre lateral (RIO DE JANEIRO/ INEPAC, s/d-h). Tombada pelo INEPAC em 1989, encontra-se em ótimo estado de conservação. Foi recentemente restaurada em 2011 e possui grande apelo turístico por ser uma das mais antigas igrejas da região.

${ }^{8}$ Está situada no centro da localidade de Rio D'Ouro e data de 1916 (ano inscrito em sua fachada). Já foi utilizada pela Associação de Moradores do Rio D'Ouro e Adjacências (AMORDA) e, atualmente, está sendo utilizada por uma igreja. Foi tombada pelo INEPAC em 1989, provisoriamente.

9 Tombada pelo INEPAC em 1989 como patrimônio estadual, porém não há fiscalização, tanto que, poucos anos atrás, a estação foi reformada por um morador que se diz herdeiro.

${ }^{10}$ Tinha uma entrada para a rua e outra para a via férrea, hoje desativada. As fachadas laterais cegas são encimadas por pequeno frontão com o nome da localidade e a data de construção (1917). Foi desativada em 1964. Tombada pelo INEPAC em 1989, encontra-se em bom estado de conservação.

${ }^{11}$ Conserva até hoje a edícula que servia de bilheteria, possui uma marquise levemente projetada para fora da platibanda, conforme o gosto art déco (RIO DE JANEIRO/ INEPAC, s/d-i). Tombada pelo INEPAC em 1989, atualmente, encontra-se em péssimo estado de conservação, e onde funcionava sua bilheteria reside um parente do antigo bilheteiro da estação.
} 
TINGUÁ, s/d). Essa Fazenda é a primeira referência dada por qualquer morador do município quando se fala em patrimônio cultural que deveria ser conservado e valorizado em Nova Iguaçu, o que não foi diferente com as crianças do Educandário Nova Grécia. Também bastante lembrados são a Torre Sineira da Igreja Nossa Senhora da Piedade de Iguaçu, localizada à margem direita do rio Iguaçu, do século XVII, o Cemitério Nossa Senhora do Rosário, construído em 1875, e o Cemitério dos Escravos, compondo o conjunto da antiga Vila Iguassú (Torre Sineira e Cemitério Nossa Senhora do Rosário) que foi tombado pelo INEPAC, em 1983, provisoriamente.

Foram inventariadas ainda edificações históricas como o Casarão do Parque Natural Municipal de Nova Iguaçu, antiga sede da Fazenda Dona Eugênia, considerado o prédio mais antigo de Nova Iguaçu; o Lar de Joaquina, construção industrial de madeira de 1930 com uma platibanda em art déco que apresenta inscrição referente ao comércio de laranjas, principal produto de exportação na época de sua construção (RIO DE JANEIRO/ INEPAC, s/d), tombado provisoriamente pelo INEPAC em 1989; o Hospital Iguassú, construído em 1935; o Centro Social São Vicente (Patronato); o Colégio Leopoldo, prédio histórico de 1921; a casa da Cruz Vermelha Brasileira no Município de Nova Iguaçu; e o Packing House, espécie de posto para embalagem de laranjas (ALBERTO, 2003). Além de obras de infraestrutura como o Reservatório Rio D'Ouro, construído em 1879 para abastecimento da capital do estado, através da captação das águas do Rio D’Ouro, que teve seu tombamento provisório pelo INEPAC em 1989 (RIO DE JANEIRO/ INEPAC, s/d-d); a represa Epaminondas Ramos, de propriedade da Companhia Estadual de Águas e Esgoto do Rio de Janeiro (CEDAE), construída em 1948, localizada junto ao limite do Parque Municipal de Nova Iguaçu; a antiga Estrada Real do Comercio (trecho dentro da Reserva Biológica do Tinguá), concluída em 1817, para ligar a Vila de Iguassú até, aproximadamente, o atual município de Paraíba do Sul, por onde se escoava café e ouro para outras regiões; e o antigo porto da Vila de Iguassú (ALBERTO, 2011).

Ainda foram levantados dados sobre a Casa de Cultura Sylvio Monteiro, onde se desenvolvem inúmeros projetos culturais, algumas exposições; e o Museu/ Instituto Afro Cultural Odé Gbomi, que destaca elementos relacionados à matriz africana no município e no estado do Rio de Janeiro - possui um acervo de, aproximadamente, 300 peças em exposição, além de uma biblioteca com 200 títulos, sendo referência no âmbito de pesquisas e exposições da cultura afro-brasileira no estado do Rio de Janeiro.

Também foram identificados elementos que compõem o patrimônio cultural imaterial presente no município, como as festas e celebrações religiosas, entre elas as Festas em louvor a Santo Antônio da Prata; a Santo Antônio; a São Jorge; a São Francisco de Assis, em Comendador Soares; e, ao Divino Espírito Santo; a Festa do Milho de Jaceruba, caracterizada como evento de caráter popular-religioso; a Folia de Reis, reconhecida como uma das mais relevantes manifestações do município de Nova Iguaçu; e, as Festas dos "ciganos incorporados", um misto de traços culturais, de sincretismo religioso e um mergulho nas religiões afro-brasileiras, da cultura cigana e dos credos católicos.

Além das festas religiosas, há também as que não guardam mais essa referência, como o Carnaval, sendo que em Nova Iguaçu há, aproximadamente, 20 escolas de samba; a Festa do Aipim, que teve origem em função do cultivo de aipim no bairro de Tinguá e em outras áreas 
do município, uma das festas mais conhecidas da Baixada Fluminense; a Festa da Banana, um evento de caráter popular, realizado pela Associação de Moradores de Jaceruba (Amoja) e pela Associação de Produtores de Jaceruba (Assoja), juntamente com a Prefeitura Municipal de Nova Iguaçu e seus órgãos representativos de incentivo e fomento, entre outras. Ainda no bairro Tinguá, situa-se a Reserva Biológica Federal do Tinguá, uma área natural de grande importância para a conservação da diversidade biológica do estado, que se estende por 26 mil hectares, grande referência e orgulho para o iguaçuano, um patrimônio cultural natural.

Retomando a abordagem sobre o patrimônio imaterial, foram inventariados ainda o projeto "Cordel com a corda toda", idealizado com o objetivo de levar cordelistas para dentro das escolas, com foco no resgate da cultura popular; e o Projeto GENTE de medicina popular. No levantamento, sobressaem-se, também, ofícios, como de artesãos de destaque no município; feirantes, da Feira da Roça, que ocorre no centro do município, bem como seus produtos, como os que têm como base a banana; grupos de arte cênicas, como o "Baixada Encena"; e áreas de lazer mais contemporâneas, como a Praça do Skate (a primeira pista da América Latina), muito apreciada pelas crianças, jovens e adolescentes.

Uma vez efetuado o levantamento e a caracterização desses bens culturais, passou-se à experimentação junto às crianças do Ensino Fundamental. Assim, foi iniciada uma experiência com crianças do $5^{\circ}$ ano do Educandário Nova Grécia, do município de Nova Iguaçu, para se compreender qual seria a melhor forma e a melhor linguagem para a produção de um material didático complementar aos livros tradicionais por elas utilizados. Realizamos uma espécie de oficina com duas turmas, uma matutina e uma vespertina, na qual introduzimos algumas questões para desenvolver com as crianças os conceitos de herança/patrimônio, patrimônio e bem cultural e buscar em seu cotidiano as respostas e compreensão dos conceitos. Na figura 1, pode-se observar uma imagem da equipe do projeto com os alunos do educandário que participaram da experimentação.

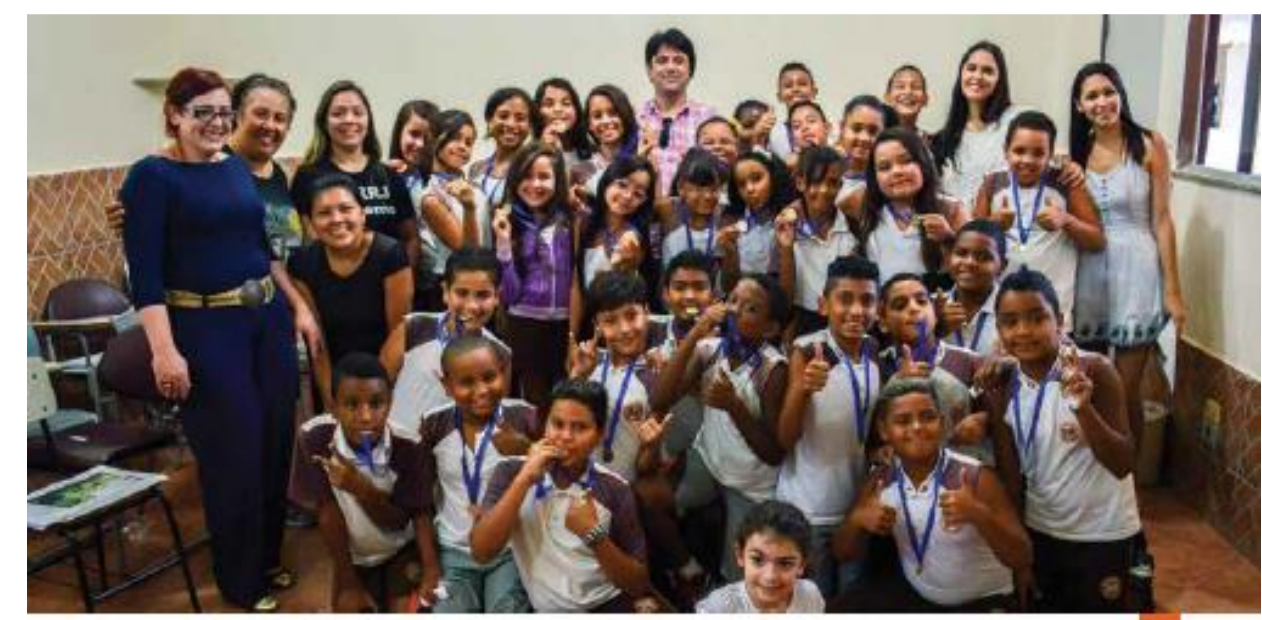

Figura 1 - Equipe de professores e alunos da UFRRJ e alunos do Educandário Nova Grécia durante as atividades do projeto. Fonte: Projeto "Patrimônio Histórico e Cultural de Nova Iguaçu: Relações Simbólicas, Sociedade e Turismo"

Então, discutimos sobre o significado de herança e ressaltamos o fato de que não somente os bens de valor monetário são importantes. Para reforçar esse entendimento, estimulamos que os alunos lembrassem elementos/itens importantes na história de suas 
famílias. Logo as crianças começaram a citar bonecas que suas mães haviam ganhado de suas avós ou de uma tia, ou mesmo um cordão que poderiam usar ao crescer, pois tinha um valor sentimental. Com o decorrer das discussões, mesmo canções ensinadas pelas mães/avós e pratos feitos por elas foram lembrados pelas crianças. Com isso, estimulamos os envolvidos a pensar no que sentiam em consequência dessas lembranças, como o gosto, o cheiro, a sensação de acolhimento.

Assim, chegamos à discussão sobre a cidade e o fato de que nela também há elementos que constituem herança/patrimônio por serem importantes para o povo que ali vive. Dessa forma, desenvolvemos o conceito de patrimônio cultural e, em seguida, voltamo-nos para Nova Iguaçu, perguntando se sabiam de algum local, item ou mesmo alguma história que fazia parte da formação e construção histórica do município. De modo bastante participativo, as crianças foram lembrando de itens que visualizavam no trajeto diário até a escola, ou quando iam ao centro da cidade com a família, ou mesmo locais que já visitaram ou que gostariam de conhecer, como a Fazenda São Bernardino, algumas igrejas, praças, entre outros. Lembraram, também, de lendas e festas que são importantes para os bairros ou as religiões, como a Festa do Aipim, a Festa do padroeiro, a Folia de Reis.

Após essa estimulação, falamos um pouco sobre a história do município e sobre o patrimônio cultural material e imaterial. Em seguida, distribuímos para circulação algumas imagens dos patrimônios e das manifestações culturais, como festas, edificações históricas, cordéis... Em um segundo momento, fornecemos folhas para as crianças e pedimos que representassem, em forma de desenho, o patrimônio cultural da cidade com o qual mais haviam se identificado, como se verifica na figura 2.

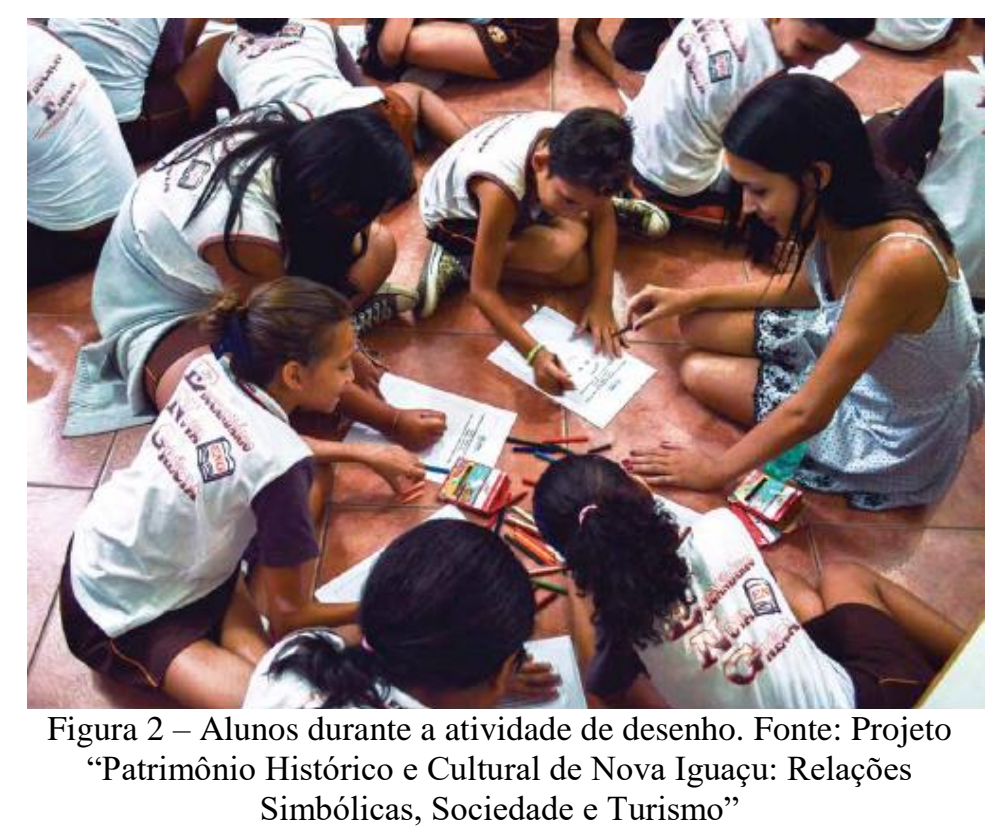

O resultado mostrou a empolgação e a criatividade das crianças, sendo que vários desses desenhos foram usados na confecção da cartilha, produto final do projeto.

É importante destacar que as professoras envolvidas com a turma, também participaram ativamente das atividades e trouxeram inúmeras contribuições para a definição da forma de 
abordagem e da linguagem mais adequadas para o desenvolvimento da cartilha. Apontaram carência de material didático para trabalhar a história local, bem como possíveis formas e estratégias para promover esse tipo de experiência.

Após a conclusão das oficinas, os professores e estudantes da UFRRJ, envolvidos com o projeto "Patrimônio Histórico e Cultural de Nova Iguaçu: Relações Simbólicas, Sociedade e Turismo", encontraram-se em reuniões técnicas para decidir o formato da cartilha. Então, o layout foi ganhando corpo e a cartilha foi construída, podendo-se observar o resultado nas imagens a seguir.

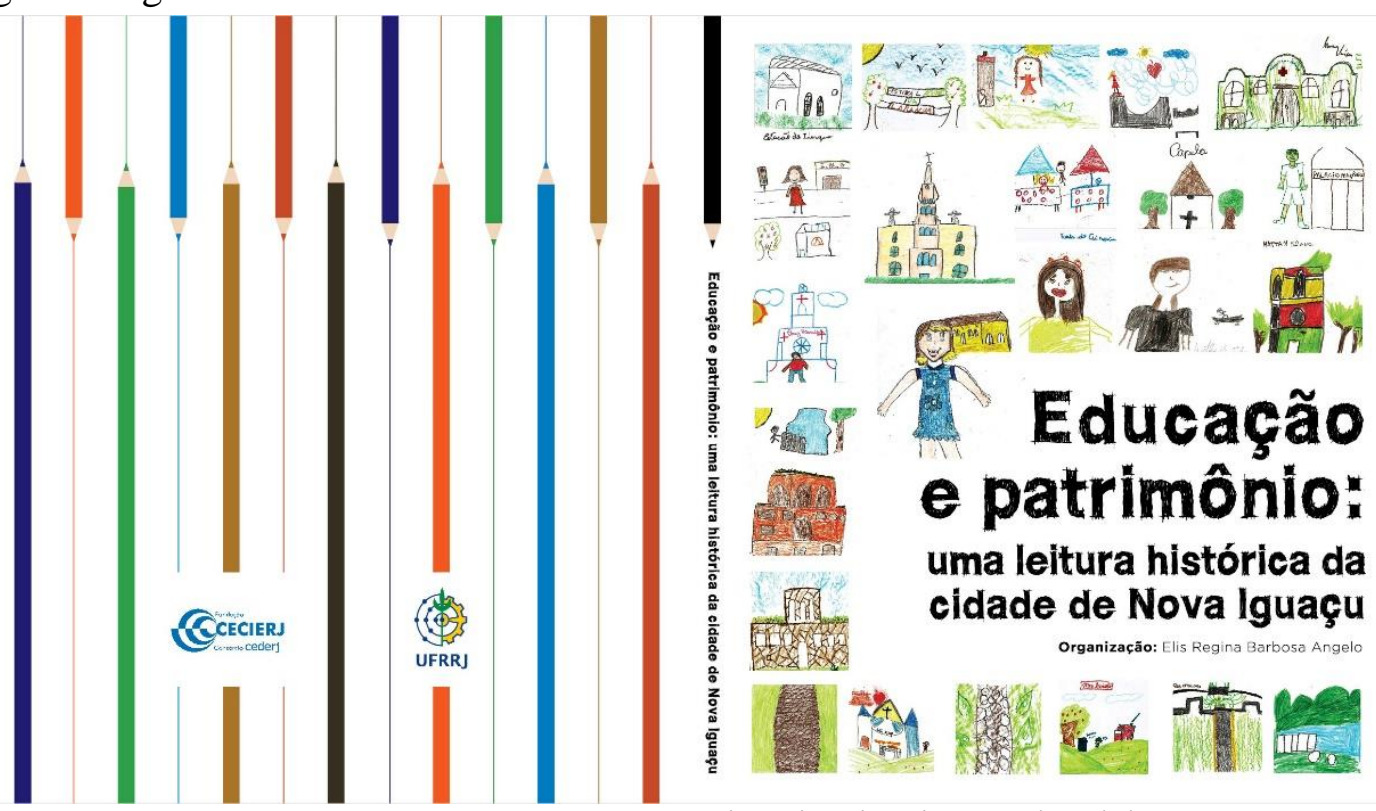

Figura 3 - Capa da cartilha produzida pelo projeto "Patrimônio Histórico e Cultural de Nova Iguaçu: Relações Simbólicas, Sociedade e Turismo". Fonte: Projeto "Patrimônio Histórico e Cultural de Nova Iguaçu: Relações Simbólicas, Sociedade e Turismo"

Os questionamentos realizados na oficina foram definidos como a melhor forma de abordagem para a cartilha (como se verifica na figura 4).

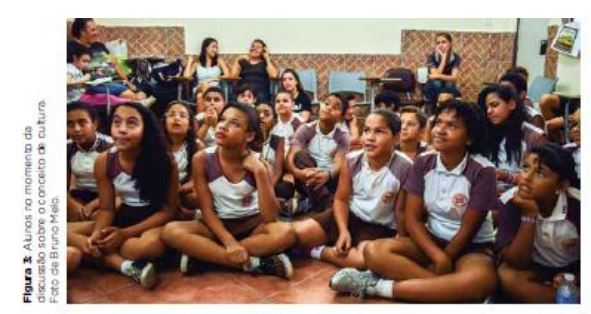

Você sabe o que é patrimônio? Já ouviu falar em herança?

A palavra património vem da ideia de herança, de pertencimento
a um lugar.

A heranca. ou património, é formada por objetos, espaccos e sa beres importantes ou de valor, deixados por pessoas queridas (nossos pais, avoss, familiares, amigos). que trazem receordacbes da história que Como o lugar onde vivemos, náo è diferente. Os grupos sociais que

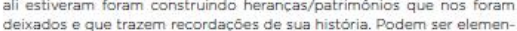
tos da natureza. saberes, obras de artistas, além de constructés, como ma igreja, uma casa de membros da familia, uma escola, entre outros espacos, objetos e memórias $E$ isso que vamos reconhecer como pas
tentar compreender esse conceito aos poucos
Você sabe o que é cultura?

Muitas vezes, achamos que a cultura é formada apenas pelos sa-

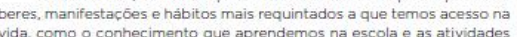
vida, como o conhecimente
que se desenvolvem em teatros a museus, entre outros lugares.

Porem, cultura e tudo 0 que faz parte da vida em sociedade: os Wostumes, habitios, atividades, regrase nommas. Epor isso que sempre a tidiano desses grupos que, de certa forma os represenentam e identificam. Assim, nâo existe uma pessoa sem cultura, e nenhuma cultura ê har do que a outra.

Portanto, o património cultural, ou heranca cultural, pode ser formado por objetos, conhecimentos, histórias, attvidades, entre outras $\mathrm{ma}$.
nifestacoes simples ou requintadas, tendo cada uma o seu valor cultural

Você conhece algum patrimônio cultural no município de Nova lguaçu?

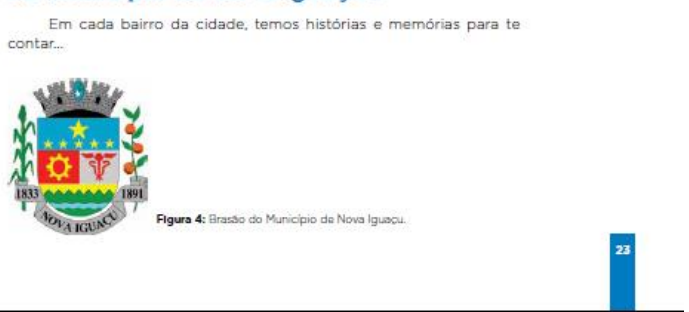


Figura 4 - Questionamentos levantados na oficina e introduzidos

como estratégia de abordagem na cartilha. Fonte: Projeto "Patrimônio Histórico e Cultural de Nova Iguaçu: Relações Simbólicas, Sociedade e Turismo"

Portanto, optamos pelo formato "perguntas e respostas", de maneira lúdica, alternando textos e imagens, e, para ilustrar a cartilha, foram usados os desenhos criados pelas crianças (como se verifica na figura 5), valorizando e estimulando a criatividade e a curiosidade dos educandos.

Você sabe como surgiu a cidade de Nova Iguaçu?

As terras que pertencem a Nova Iguacu faziam parte da Capita. la de Säo Vicente e eram propriedade de Martim Afonso de Souza.. dias atuais. ocupando também a àrea onde hoje se localizam as cidades Roxo, Japeri e Mesquita

Nem sempre a cidade teve esse nome!

A regia em que hoje se localiza Nova Iguacu era conhecida como a freguesia de Nossa Senhora da Piedade do Iguassu (escrita da época),
Após a construça da Estrada de Ferro, a sede da cidade passou pare Após a construcáo da Estrada de Ferro, a sede da cidade passou para A regiâo de Tinguá, antiga sede, ficou entâo conhecida como Iguaçu Velho.

Você sabe quais eram as atividades econômicas desenvolvidas na sua cidade ao longo de sua história?

Por volta de 1833, destacavam-se as plantaḉes de cana-de-acúcar, arroz, milho, feịăo, mandioca e café, que eram transportados até os portos do Ric iguassu, de onde partiam para o porto do Rio de Jahento

30 de Queimados, Duque de Caxias, Nilópolis, Sáo Joào de Meriti, Belfor

A sede da cidade se localizava onde hoje fica a regiảo de Tinguáe

A partir de 1930, com as plantac6es de laranja, Nova Iguaçu ganhou o apelido de Cidade Perfume, pois quem passava por aqui podia
sentir o cheiro agradável dos laranijis. As laranijs eram exportadas piata saises como Argentina e Uruguai, mas, corn a Segunda Guerra Mundia. as exportacóes foram interrompidas e muitas frutas apodreceram no
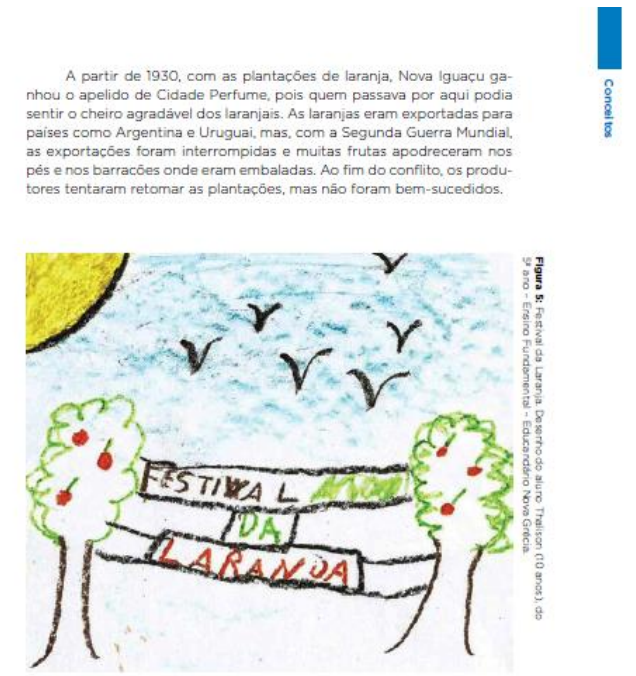

Figura 5 - Desenhos criados pelas crianças, usados e mesclados com questionamentos e textos. Fonte: Projeto "Patrimônio Histórico e Cultural de Nova Iguaçu: Relações Simbólicas, Sociedade e Turismo"

Os bens culturais foram, ainda, representados com desenhos elaborados pelas crianças. Como exemplo, temos a Estação de Tinguá e a Fazenda São Bernardino, ambas desenhadas por inúmeras crianças, uma vez, serem os patrimônios mais trabalhados nas escolas, e sobre os quais as crianças tinham mais referências, como se observa na figura 6.
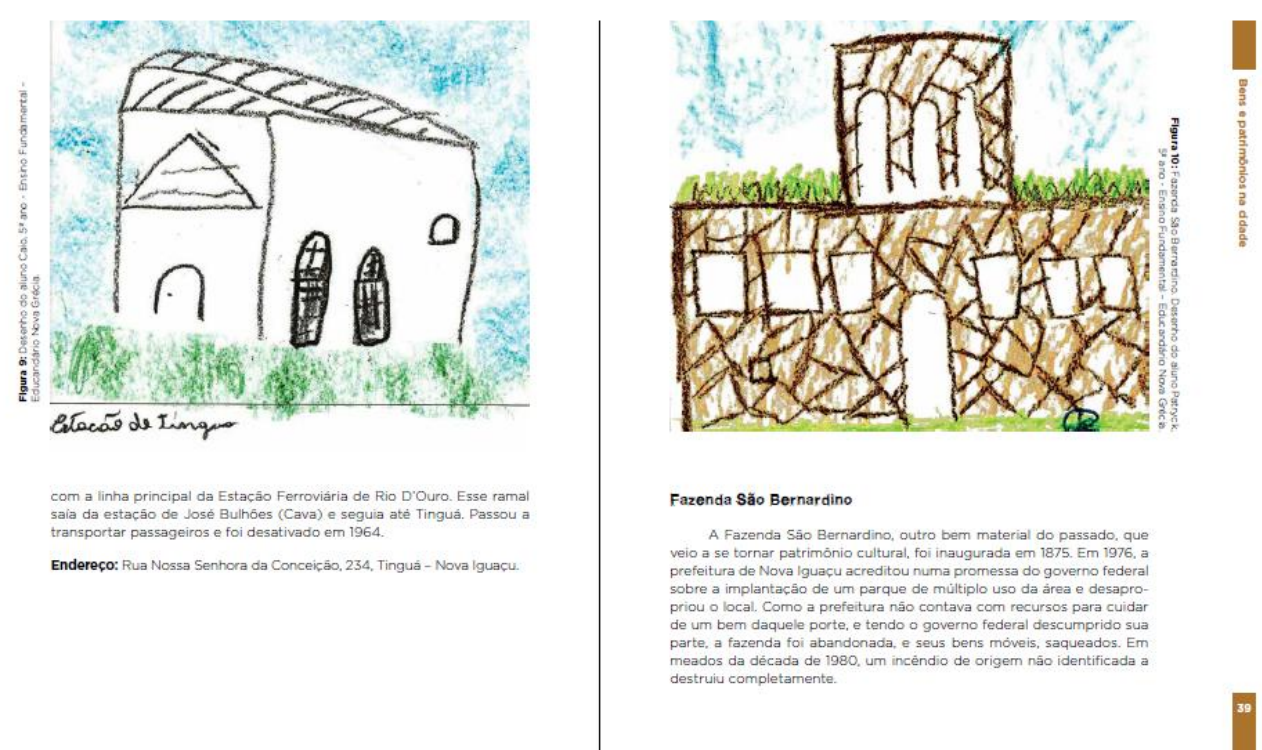

com a linha principal da Estaçáo Ferroviária de Rio D’Ouro. Esse rama sala da estaḉo de José Bulhóes (Cava) e segu
transportar passageiros e foi desativado em 1964.

Endereco: Rue Nossa Sentora da Conceicas. 234 Tingus - Nova

Fazenda São Bernardino

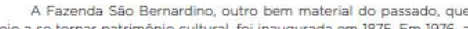

veio a se tornar património cultural, foi inaugurada em 1875. Em 1976. a prefeitura de Nova Iguaçu acreditou numa promessa do governo federal
sobre a implantacáa de um parque de mútiplo uso da ârea e desapro. priou o local. Cormo a prefeitura náo contava com recursos para cuidar de umn bem daquele porte, e tendo o governo federal descumprido sua parte, a fazenda foi abandonada, e seus bens móveis, saqueados. Em
meados da década de 1980, um incéndio de origem náo identificada meados da decada de 19 per.

Figura 6 - Representação da Estação de Tinguá e da Fazenda São Bernardino na cartilha. Fonte: Projeto "Patrimônio Histórico e Cultural de Nova Iguaçu: Relações Simbólicas, Sociedade e Turismo" 
Usamos ainda fotos produzidas durante o trabalho de campo, como se verifica na figura 7.

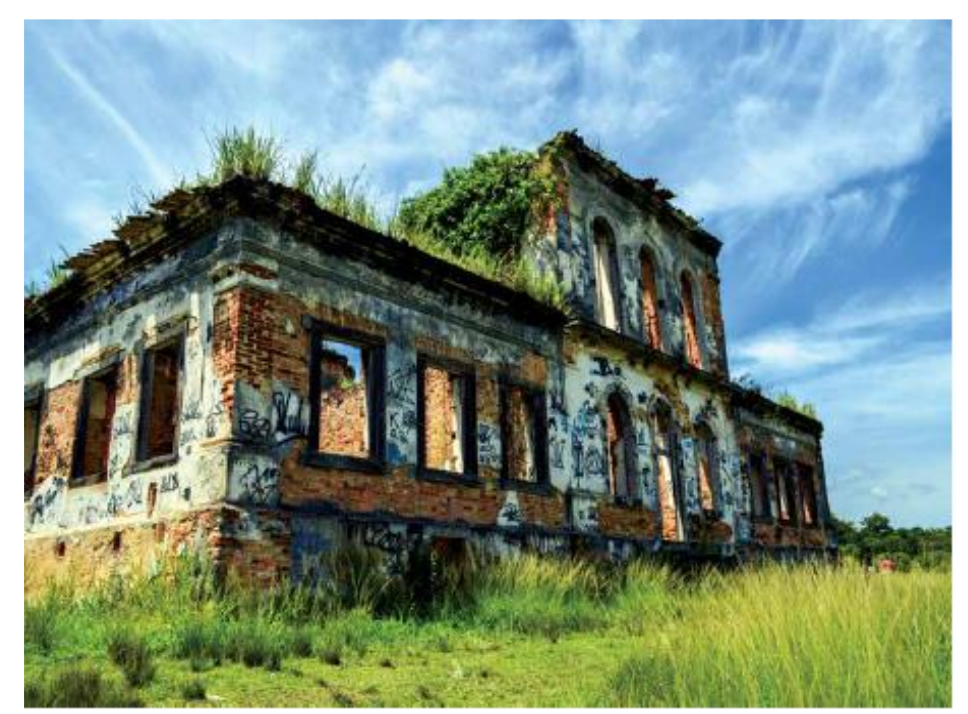

Figura 7 - Fotografia da Fazenda São Bernardino, também representada na cartilha. Fonte: Projeto "Patrimônio Histórico e Cultural de Nova Iguaçu: Relações Simbólicas, Sociedade e Turismo"

A cartilha ainda conta com mapas de localização dos patrimônios (Figuras 8 e 9), para que as crianças possam se situar, geograficamente, e o material possa ser trabalhado dentro de disciplinas como Geografia.
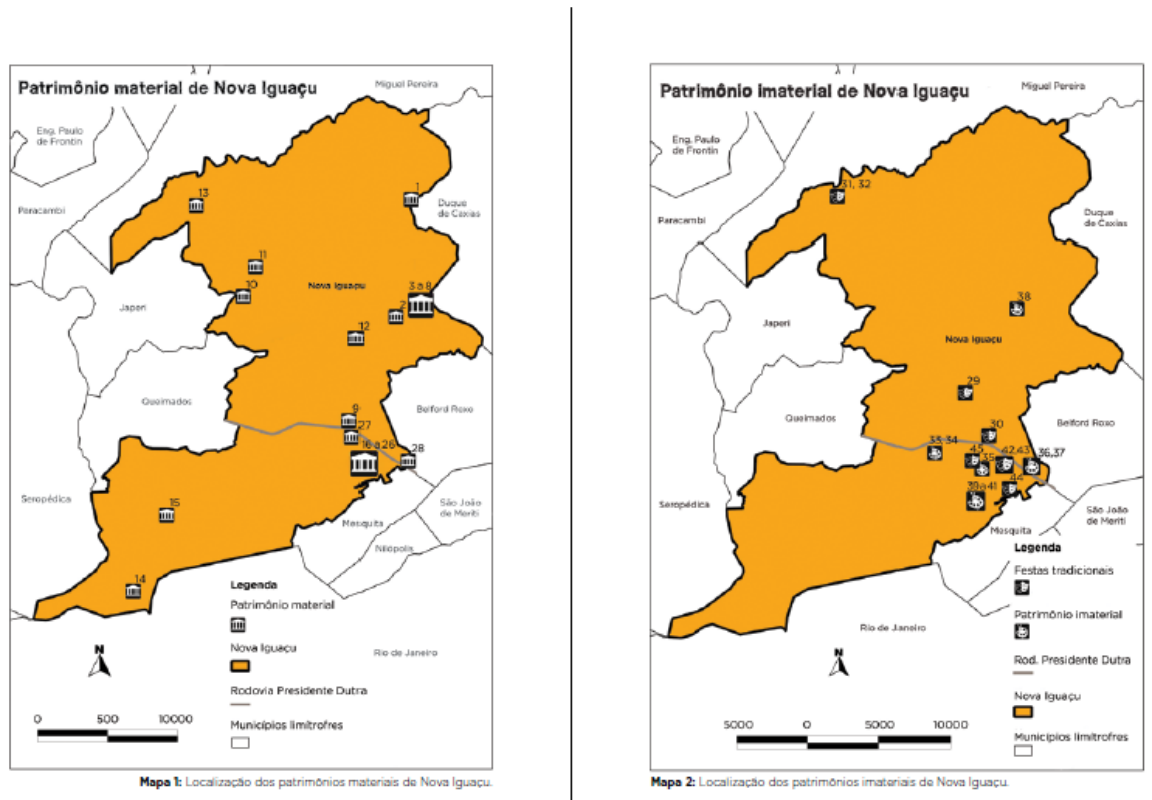

Figura 8 - Mapas presentes na cartilha. Fonte: Projeto "Patrimônio Histórico e Cultural de Nova Iguaçu: Relações Simbólicas, Sociedade e Turismo" 

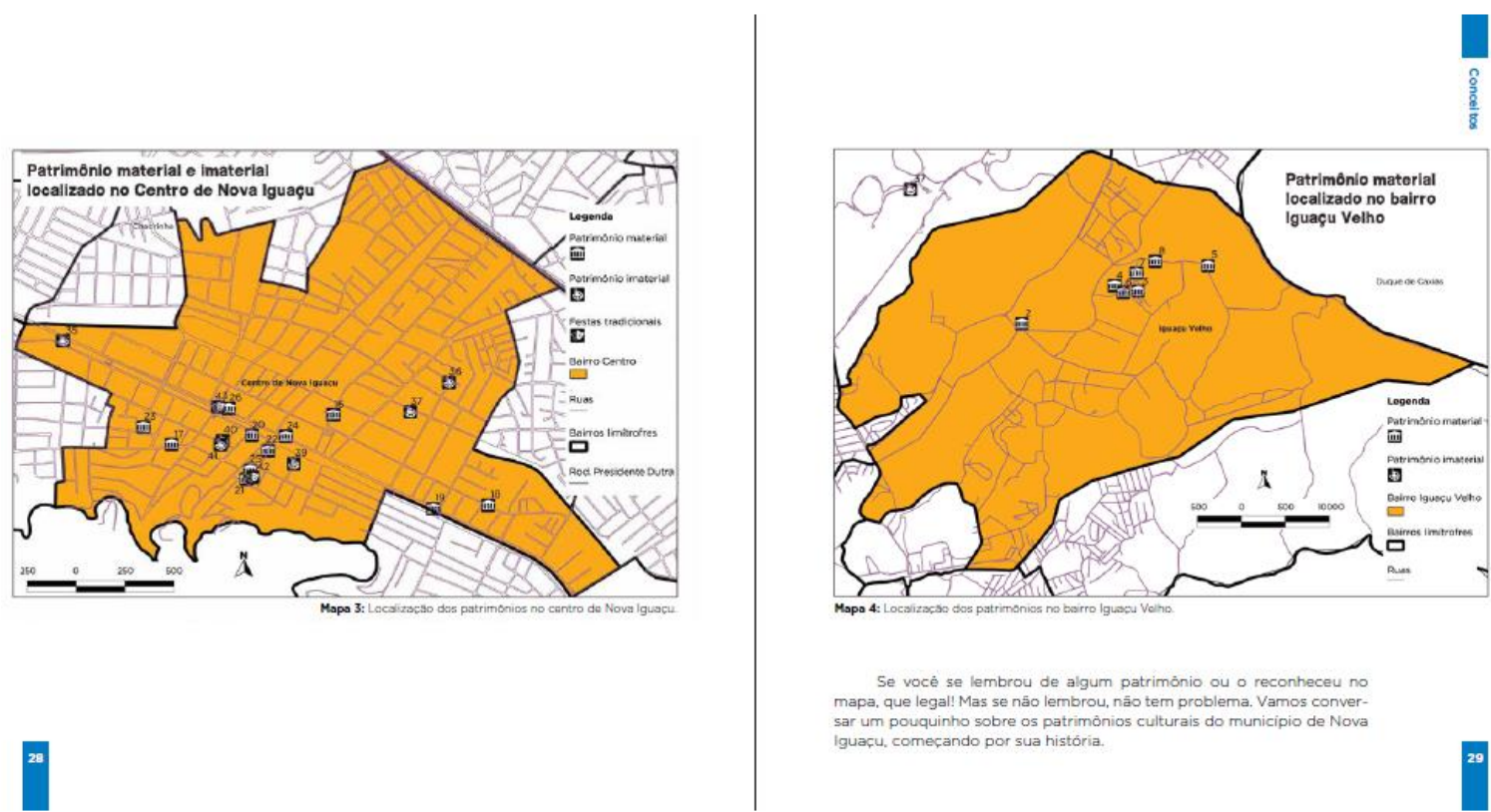

Figura 9 - Mapas presentes na cartilha. Fonte: Projeto "Patrimônio Histórico e Cultural de Nova Iguaçu: Relações Simbólicas, Sociedade e Turismo"

Sem a pretensão de esgotar essa discussão, no próximo tópico traçamos algumas considerações sobre os desdobramentos desse projeto.

\section{Traçando algumas considerações}

Mapear e identificar o patrimônio histórico e cultural de Nova Iguaçu - RJ abriu espaço para que a educação patrimonial se inicie com o "reconhecimento" da cidade, partindo de sua história, suas memórias, constituídas por sujeitos e objetos, além das manifestações culturais, como legado para as gerações seguintes. Uma vez que, segundo Tolentino (2013, p.5),

[...] os processos educativos devem primar pela construção coletiva e democrática do conhecimento, por meio do diálogo permanente entre os agentes culturais e sociais e pela participação efetiva das comunidades detentoras das referências culturais onde convivem diversas noções de patrimônio cultural.

As imagens produzidas pela cidade definem um pouco de sua história; as continuidades, os hábitos, os valores e os costumes vão desenhando as identidades e cristalizando-as nos bens de natureza material. Esse caminho percorrido entre pessoas, objetos e lugares vai formando um legado e transformando o território em espaço social vivido, com as experiências, memórias e materiais geracional e, temporalmente, construídos pelos lugares.

A cartilha do patrimônio da cidade é uma iniciativa que busca trazer para a educação de base os movimentos culturais desenvolvidos de forma colaborativa, pelos quais os diversos sujeitos produzem, dialogam e criam os sentidos e significados dos lugares, saberes e formas da sua região. Assim, vai despontando entre os iguaçuanos uma nova forma de se ver e de existir para si e para o mundo. Esse é um processo que se inicia com objetivos delineados, a 
partir de iniciativas acadêmicas, mas, sem dúvida, envolve um longo caminho, o aprendizado do reconhecimento da história da cidade.

O projeto de educação patrimonial possibilitou para alunos, professores e pesquisadores da Universidade Federal Rural do Rio de Janeiro estabelecer um elo com a prática e o "conhecer" da cidade. Essa leitura pressupõe uma interlocução com a história local e aponta caminhos para a formação dos valores dos cidadãos com base na informação e na multiplicação dos saberes. Ademais, os desenhos de "autorretrato" e dos "lugares que eu conheço" criados pelos alunos do Educandário Nova Grécia forneceram não apenas imagens para a construção da cartilha, mas o "olhar" e a "colaboração" tão importantes para a multiplicação do processo de educação.

Antes de encerrar, cabe destacar a dificuldade encontrada para o estabelecimento de parcerias, visando viabilizar a reprodução da cartilha, em grande escala. Foram inúmeras tentativas, desde 2015, com o poder público, sem obter sucesso, embora o projeto contemplasse a Lei Municipal no 4.092 de 28 de junho de 2011, que institui o Plano Diretor Participativo e o Sistema de Gestão Integrada e Participativa da cidade de Nova Iguaçu. Nessa lei, em sua seção I, há referências ao "Programa Pertencer à Nova Iguaçu”, que, segundo o artigo 67, “[...] compreende o conjunto das ações do poder público necessárias para que se reforce o sentimento de pertencimento do cidadão iguaçuano à sua cidade" (NOVA IGUAÇU, 2011, p.21). No seu artigo 68 consta ainda que o Programa Pertencer à Nova Iguaçu compreende o seguinte conjunto de ações estratégicas:

I. preservação e valorização dos eixos históricos da cidade;

II. identificação e qualificação dos marcos de referência da cidade, tanto do ponto de vista histórico quanto cultural e ambiental;

III. identificação, valorização e qualificação das entradas da cidade;

IV.levantamento, identificação e preservação de bens do patrimônio histórico e cultural da cidade;

IV.resgate da memória da cidade;

V. promoção de atividades culturais.

Além disso, cabe ressaltar que no artigo 72 da referida lei, inciso III, está explícito que “o resgate da memória da cidade compreenderá as seguintes ações prioritárias":

I. resgate, tratamento e acondicionamento da documentação histórica, com criação de um arquivo histórico e de uma biblioteca especializada;

II. promover atividades que levem a história de Nova Iguaçu a todos os bairros;

III. realizar atividades nas escolas públicas municipais que valorizem a memória da cidade, incluindo o ensino da história da cidade de Nova Iguaçu no currículo do ensino fundamental, na rede municipal de ensino;

IV.identificar e preservar as culturas religiosas remanescentes de quilombolas e religiões afro descendentes.

Portanto, ações essas desenvolvidas no projeto de educação patrimonial que resultou na cartilha aqui apresentada. Vale destacar que o IPHAN, citado por Tolentino (2013, p.7), entende a educação patrimonial como sendo: 
[...] os processos educativos formais e não-formais que têm como foco o patrimônio cultural apropriado socialmente como recurso para a compreensão sócio-histórica das referências culturais em todas as suas manifestações, com o objetivo de colaborar para o seu reconhecimento, valorização e preservação.

Encerramos este artigo com a pretensão de ter iniciado a discussão sobre o patrimônio cultural de Nova Iguaçu e da Baixada Fluminense, bem como a aspiração de ter destacado a possibilidade de desenvolvimento de atividades que, além de gerar emprego e renda à população, sirvam como estratégia para mudar a imagem da cidade e da região como um todo, o turismo e a educação patrimonial, sem esgotar a temática.

Gostaríamos ainda de deixar registrado nosso agradecimento a toda a equipe que participou do projeto "Patrimônio Histórico e Cultural de Nova Iguaçu: Relações Simbólicas, Sociedade e Turismo", em especial à docente Monika Richter, responsável pela produção do mapas, aos discentes Jéssica Andrade Costa (bolsista), Amanda Lopes da Silva, Andrea Gomes Carvalho da Silva, Bianca Rosa do Nascimento da Rocha, Bruno dos Santos Melo, Elisa Paes Silva, Júlio Santana (voluntários), alunos, professores, coordenadores pedagógicos e diretores do Educandário Nova Grécia.

\section{Referências bibliográficas}

ALBERTO, Ney. De Iguassú a Nova Iguaçu. 170 anos - 1833 a 2003. $2^{\text {a }}$ edição. Nova Iguaçu: Prefeitura Municipal de Nova Iguaçu, 2003.

ALBERTO, Ney. Estrada Real do Comércio. Folha do Iguassú. 31 ago. 2011. Disponível em <http://jornalfolhadoiguassu.blogspot.com.br/2011/08/estrada-real-do-comercio.html>. Acesso em: 05 mai. 2014.

ANDRADE, Rodrigo Melo Franco de. Rodrigo e o SPHAN - Coletânea de textos sobre o patrimônio cultural. Rio de Janeiro: MinC/ Fundação Nacional Pró-Memória, 1987.

BRASIL. Instituto Brasileiro de Geografia e Estatística - IBGE. Brasil / Rio de Janeiro / Nova Iguaçu. Produto Interno Bruto dos Municípios. 2015. Disponível em: $<$ https://cidades.ibge.gov.br/brasil/rj/novaiguacu/pesquisa/38/47001?tipo=ranking\&indicador=46997\&ano=2015 > . Acesso em: 2017.

DO NOME. Informação e Serviços. Turismo e viagem. Pontos turísticos em Nova Iguaçu. 11 ago. 2011. Disponível em <http://donome.com.br/pontos-turisticos-em-nova-iguacu/>. Acesso em: 09 mai. 2014.

ESTAÇÕES FERROVIÁRIAS DO BRASIL. Estado do Rio de Janeiro. E. F. Central do Brasil - E. F. Rio de Ouro. s/d. Disponível em: $\langle$ http://www.estacoesferroviarias.com.br/efcb_rj_riodeouro/efrio_ouro.htm $>$. Acesso em: 26 abr. 2014. 
MONUMENTOS DO RIO. Cidades do Estado. Nova Iguaçu. Capela de Nossa Senhora de Guadalupe. s/d. Disponível em: <http://www.monumentosdorio.com.br/base/cidades/050.htm>. Acesso em: 28 abr. 2014.

NOVA IGUAÇU (Município). Lei $n^{o}$. 4.092, de 28 de junho de 2011. Nova Iguaçu, 28 jun. 2011. <https://pt.wikisource.org/wiki/Lei_Municipal_de_Nova_Igua\%C3\%A7u_4092_de_2011>. Acesso em: abril 2018.

PARÓQUIA NOSSA SENHORA DA CONCEIÇÃO - TINGUÁ. Fazenda São Bernardino. $\mathrm{s} / \mathrm{d}$.

$<$ http://paroquianossasenhoradaconceicaotingua.blogspot.com.br/2008/04/fazenda-so-

bernardino.html >. Acesso em: 26 abr. 2014.

PARÓQUIA SANTO ANTÔNIO DE JACUTINGA. Paróquia. s/d. Disponível em: <http://santoantoniojacutinga.com/index.php/paroquia >. Acesso em: 12 mai. 2014.

RIO DE JANEIRO (Estado). INEPAC - Instituto Estadual do Patrimônio Cultural. Patrimônio Cultural - Bens tombados. Antiga Estação Ferroviária de Rio d'Ouro. s/d-a. Disponível em: $<$ http://www.inepac.rj.gov.br/index.php/bens_tombados/detalhar/169>. Acesso em: 30 abr. 2014.

RIO DE JANEIRO (Estado). INEPAC - Instituto Estadual do Patrimônio Cultural. Patrimônio Cultural - Bens tombados. Antiga Estação Ferroviária de Tinguá. s/d-b. Disponível em: <http://www.inepac.rj.gov.br/index.php/bens_tombados/detalhar/168>. Acesso em: 30 abr. 2014.

RIO DE JANEIRO (Estado). INEPAC - Instituto Estadual do Patrimônio Cultural. Patrimônio Cultural - Bens tombados. Lar de Joaquina e galpão ao fundo. s/d-c. Disponível em: $<$ http://www.inepac.rj.gov.br/index.php/bens_tombados/detalhar/169>. Acesso em: 30 abr. 2014.

RIO DE JANEIRO (Estado). INEPAC - Instituto Estadual do Patrimônio Cultural. Patrimônio Cultural - Bens tombados. Reservatório de Rio d'Ouro. s/d-d. Disponível em: $<$ http://www.inepac.rj.gov.br/index.php/bens_tombados/detalhar/171>. Acesso em: 30 abr. 2014.

RIO DE JANEIRO (Estado). INEPAC - Instituto Estadual do Patrimônio Cultural. Patrimônio Cultural - Bens tombados. Capela da Fazenda da Posse. s/d-e. Disponível em: $<$ http://www.inepac.rj.gov.br/index.php/bens_tombados/detalhar/162>. Acesso em: $30 \mathrm{abr}$. 2014.

RIO DE JANEIRO (Estado). INEPAC - Instituto Estadual do Patrimônio Cultural. Patrimônio Cultural - Bens tombados. Capela Nossa Senhora de Guadalupe. s/d-f. Disponível em: $<$ http://www.inepac.rj.gov.br/index.php/bens_tombados/detalhar/164>. Acesso em: 30 abr. 2014.

RIO DE JANEIRO (Estado). INEPAC - Instituto Estadual do Patrimônio Cultural. Patrimônio Cultural - Bens tombados. Igreja Nossa Senhora Conceição de Marapicu. s/d-g. Disponível em: 〈http://www.inepac.rj.gov.br/index.php/bens_tombados/detalhar/163>. Acesso em: 30 abr. 2014.

RIO DE JANEIRO (Estado). INEPAC - Instituto Estadual do Patrimônio Cultural. Patrimônio Cultural - Bens tombados. Igreja Santo Antônio de Jacutinga, atual Igreja da Prata. s/d-h. 
Disponível em: <http://www.inepac.rj.gov.br/index.php/bens_tombados/detalhar/161 > Acesso em: 30 abr. 2014.

RIO DE JANEIRO (Estado). INEPAC - Instituto Estadual do Patrimônio Cultural. Patrimônio Cultural - Bens tombados. Antiga Estação de Vila de Cava. s/d-i. Disponível em: $\langle$ http://www.inepac.rj.gov.br/index.php/bens_tombados/detalhar/170 $>$. Acesso em: $30 \mathrm{abr}$. 2014.

TOLENTINO, Atila Bezerra (Org.). Educação Patrimonial: Educação, Memórias e Identidades. Caderno temático 3. João Pessoa: IPHAN, 2013.

VAZ, Lilian Fessler; JACQUES, Paola Berenstein. Reflexões sobre o uso da cultura nos processos de revitalização urbana. Anais do IX Encontro Nacional da Anpur: Ética, Planejamento e construção democrática do espaço. Rio de Janeiro: ANPUR, 2001, p.664-674. 